\title{
Experimental Study on Evaporation Heat Transfer Characteristics of R32 in A Plate Heat Exchanger
}

\author{
Jaewan Yang, DongChan Lee, Yongchan Kim \\ Department of Mechanical Engineering, Korea University \\ 145 Anam-ro, Seongbuk-gu, Seoul 02841, Republic of Korea \\ koala5555@korea.ac.kr; ldc1120@korea.ac.kr; yongckim@korea.ac.kr
}

\begin{abstract}
This study experimentally investigates the evaporation heat transfer and frictional pressure drop characteristics of R32 in a plate heat exchanger with a chevron angle of $60^{\circ}$. The evaporation heat transfer coefficient and friction factor are measured at mass fluxes of 50,70 , and $90 \mathrm{~kg} / \mathrm{m}^{2} \mathrm{~s}$, a heat flux of $6.45 \mathrm{~kW} / \mathrm{m}^{2}$, and saturation temperatures of 5 and $15^{\circ} \mathrm{C}$. The heat transfer coefficient increases with the mass flux, saturation temperature, and vapor quality because the forced convective boiling is dominant in this study. The frictional pressure drop also increases gradually with the vapor quality owing to the high velocity difference between the two phases. R32 exhibits a higher heat transfer coefficient and frictional pressure drop than R410A due to the high thermal conductivity and low vapor density. Furthermore, the friction factor of R32 decreases up to a certain quality (0.4) and then increases slightly afterwards. The frictional pressure drop of R32 is greater than R410A owing to the influence of density despite the lower viscosity. The friction factor of R32 is also higher than R410A due to the lower liquid and vapor density.
\end{abstract}

\section{Keywords: R32, Heat transfer coefficient, Friction factor, Frictional pressure drop, Plate heat exchanger}

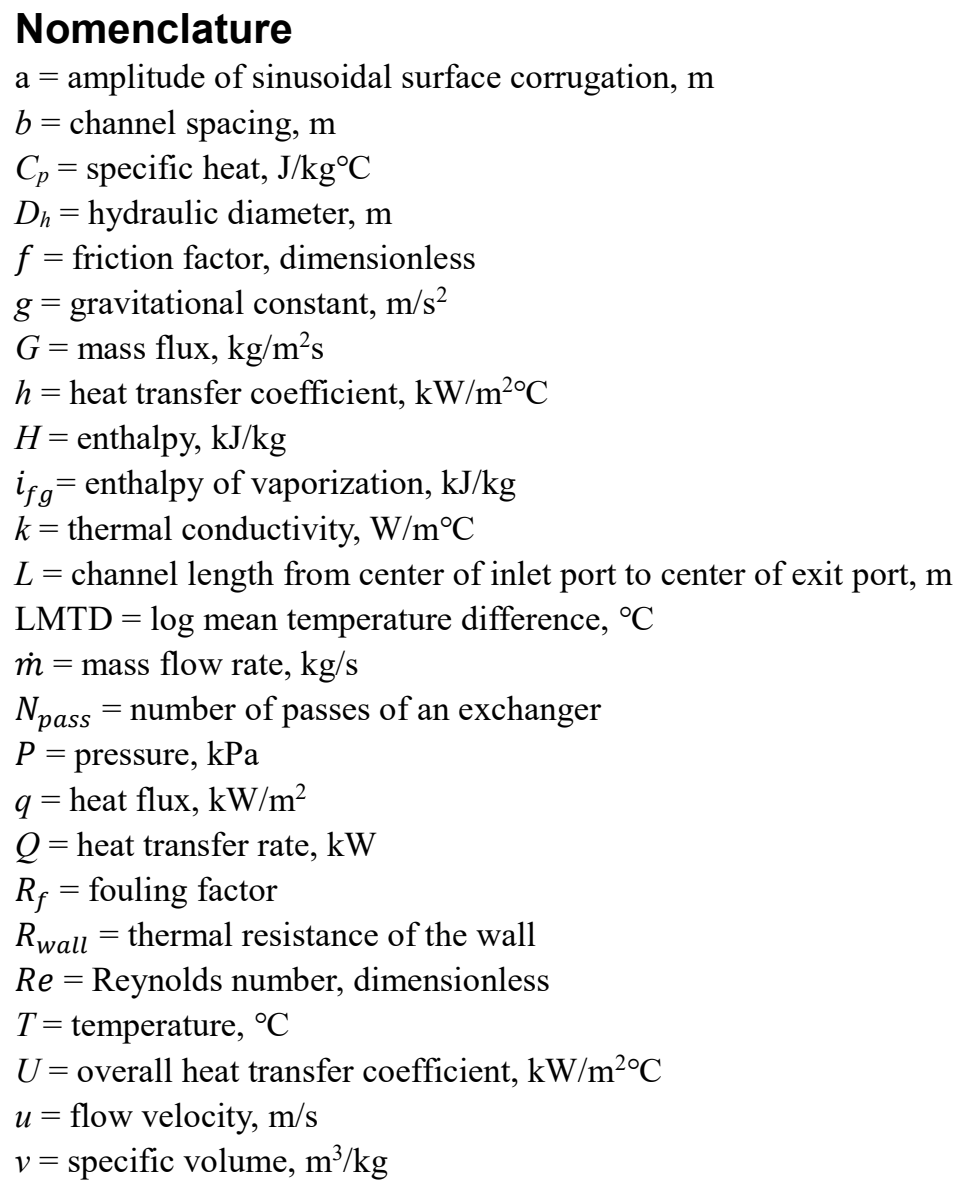


$w=$ width of the plate, $\mathrm{m}$

$X=$ vapor quality

$\Delta P=$ pressure drop, $\mathrm{kPa}$

$\Delta T=$ temperature difference, ${ }^{\circ} \mathrm{C}$

$\Delta X=$ quality change in the exchanger

$\beta=$ chevron angle of plate heat exchanger, degrees

$\Lambda=$ corrugation wavelength, $\mathrm{m}$

$\rho=$ density, $\mathrm{kg} / \mathrm{m}^{3}$

$\mu=$ viscosity, $\mathrm{Ns} / \mathrm{m}^{2}$

Subscripts

$\mathrm{a}=$ acceleration

ave $=$ average

ele $=$ elevation

$\exp =$ experiment

$\mathrm{fg}=$ difference between liquid and vapor phase

$\mathrm{i}, \mathrm{o}=$ at inlet and exit of test section

$1, \mathrm{~g}=$ liquid and vapor phase

$\mathrm{m}=$ average value for the two-phase mixture or between the inlet and outlet

$R=$ refrigerant

sat $=$ saturated state

$\mathrm{W}=$ water

wall $=$ wall of the plate heat exchanger

pre $=$ pre-heater

ov $=$ overall

\section{Introduction}

EU F-gas regulation [1] makes the selection of refrigerants more difficult by regulating high GWP refrigerants to phase out $79 \%$ of F-gas by 2030. Among the conventional refrigerants, R410A, which is mainly used in chillers or heat pumps, should be replaced due to its high GWP (2088). There are many candidates for replacement of R410A. Properties of the alternative refrigerants of R410A are shown in Table 1. Among the given candidates, R32 can be considered as the most promising alternative refrigerant because of its low GWP and density, high thermal conductivity and latent heat.

Table 1: Properties of R410A and its alternatives.

\begin{tabular}{|l|l|l|l|l|}
\hline & R410A & R32 & R446A & R452B \\
\hline Critical pressure $[\mathrm{kPa}]$ & 4901 & 5780 & 5725.2 & 5220.1 \\
\hline Critical temperature $[\mathrm{K}]$ & 344.5 & 351.1 & 359.1 & 350.2 \\
\hline Boiling temperature $[\mathrm{K}]$ & 221.7 & 221.3 & 223.4 & 222.5 \\
\hline Latent heat $[\mathrm{kJ} / \mathrm{kg}]$ & 272.9 & 368.9 & 327.2 & 331.8 \\
\hline $\begin{array}{l}\text { Liquid Thermal conductivity } \\
{[\mathrm{mW} / \mathrm{m} \cdot \mathrm{K}]}\end{array}$ & 94.73 & 133.54 & 113.79 & 103.57 \\
\hline $\begin{array}{l}\text { Vapor Thermal conductivity } \\
{[\mathrm{mW} / \mathrm{m} \cdot \mathrm{K}]}\end{array}$ & 14.09 & 13.43 & 14.7 & 15.16 \\
\hline Liquid viscosity $[\mu \mathrm{Pa} / \mathrm{s}]$ & 134.11 & 127.31 & 125.2 & 114.7 \\
\hline Vapor viscosity $[\mu \mathrm{Pa} / \mathrm{s}]$ & 13.02 & 12.26 & 12.73 & 12.93 \\
\hline Liquid density $\left[\mathrm{kg} / \mathrm{m}^{3}\right]$ & 1106.3 & 1000.9 & 1001.4 & 993.5 \\
\hline Vapor density $\left[\mathrm{kg} / \mathrm{m}^{3}\right]$ & 48.86 & 35.19 & 42.51 & 52.39 \\
\hline GWP & 2088 & 650 & 470 & 677 \\
\hline Safety class & $\mathrm{A} 1$ & $\mathrm{~A} 2 \mathrm{~L}$ & $\mathrm{~A} 2 \mathrm{~L}$ & $\mathrm{~A} 2 \mathrm{~L}$ \\
\hline
\end{tabular}




\section{Experimental setup and test conditions}

\subsection{Experimental setup}

Fig. 1 shows a schematic of the experimental setup. The experimental setup consisted of a refrigerant, a water, and a chiller loop. A magnetic pump circulated the refrigerant through the test section, and the vapor quality of the refrigerant at the inlet of the test section was controlled by a pre-heater. The refrigerant evaporated in the test section by exchanging heat with water and condensed to the initial condition through exchanging heat with ethylene-glycol. All the temperatures and pressures were recorded by sensors and used to calculate the evaporation heat transfer coefficient and frictional pressure drop. The operating conditions of this experiment are shown in Table 2.

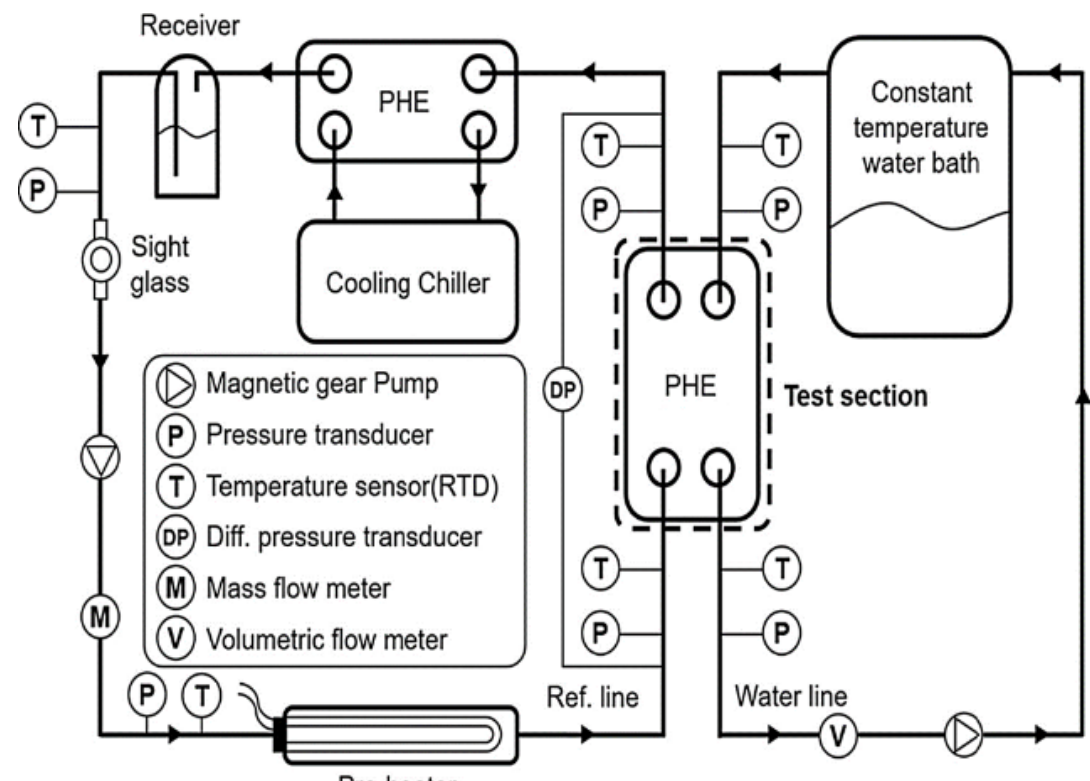

Pre-heater

Fig. 1: Schematic diagram of the experimental setup.

Table 2: Operating conditions for experiments.

\begin{tabular}{|l|l|}
\hline Data & Operating condition \\
\hline Evaporating temperature $\left({ }^{\circ} \mathrm{C}\right)$ & 5,15 \\
\hline Mass flux $\left(\mathrm{kg} / \mathrm{s} \cdot \mathrm{m}^{2}\right)$ & $50,70,90$ \\
\hline Quality & $0.01-0.9$ \\
\hline Heat flux $\left(\mathrm{kW} / \mathrm{m}^{2}\right)$ & 6.45 \\
\hline
\end{tabular}

\subsection{Plate heat exchanger}

A plate heat exchanger is advantageous in terms of maintenance by separating each single plate. Also, it is widely used because of its high heat transfer performance and low fouling effect. The plate heat exchanger is characterized by two factors: corrugation aspect factor $(\gamma)$ and enlargement factor $(\varphi)$, as given in Eqs. (1) and (2).

$$
\gamma=\frac{4 a}{\Lambda}=\frac{2 b}{\Lambda}
$$

where $a$ denotes the corrugation amplitude and $\Lambda$ denotes the corrugation wavelength. The enlargement factor $(\varphi)$ can be approximated by using a non-dimensional parameter $A$, as shown in Eqs. (2) and (3) [2]. 


$$
\begin{gathered}
A=\frac{2 \pi a}{\Lambda} \\
\varphi(A) \cong \frac{1}{6}\left(1+\sqrt{1+A^{2}}+4 \sqrt{1+A^{2} / 2}\right)
\end{gathered}
$$

As shown in Fig. 2, the plate heat exchanger with a chevron angle of $60^{\circ}$ was used as an evaporator.

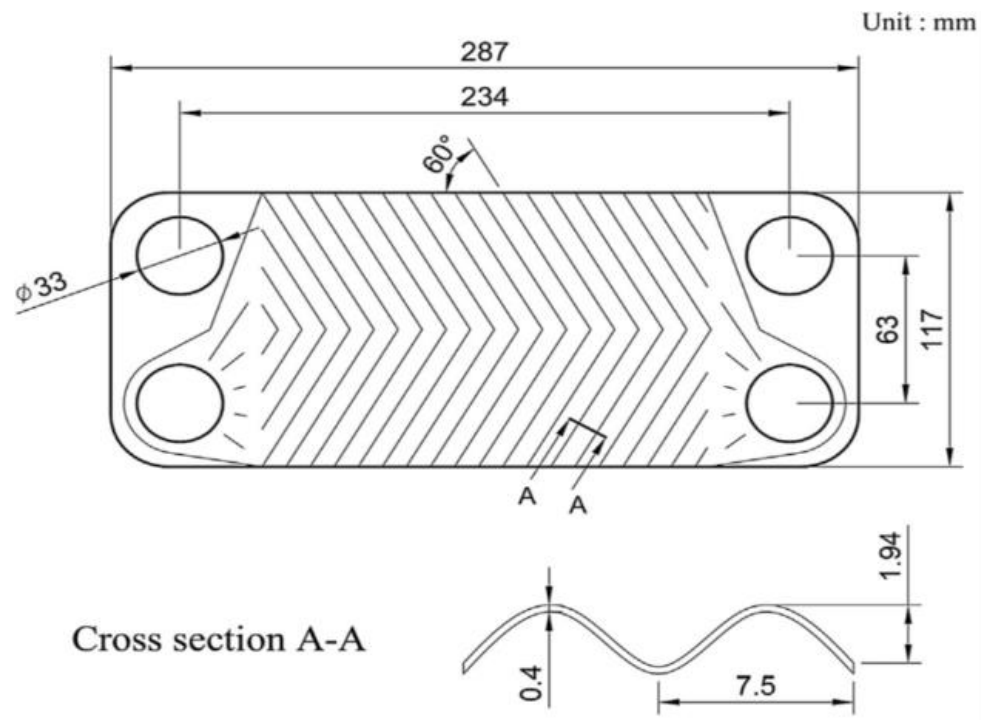

Fig. 2: Geometry of the PHE.

\section{Data reduction}

\subsection{Heat transfer coefficient}

As shown in Eq. (4), the water-side heat transfer coefficient was calculated through the modified Wilson plot method technique [3] using the water-to-water preliminary experiment data. Validation graph of $\mathrm{R}_{\mathrm{ov}}$ actual to $\mathrm{R}_{\mathrm{ov}}$ calculated by $N u_{w}$ correlation is shown in Fig. 3.

$$
N u_{w}=0.02628 \operatorname{Re}_{w}^{1.21} \operatorname{Pr}_{w}^{1 / 3}
$$

The overall heat transfer coefficient was calculated by the LMTD method, which is shown in Eqs. (5) - (7).

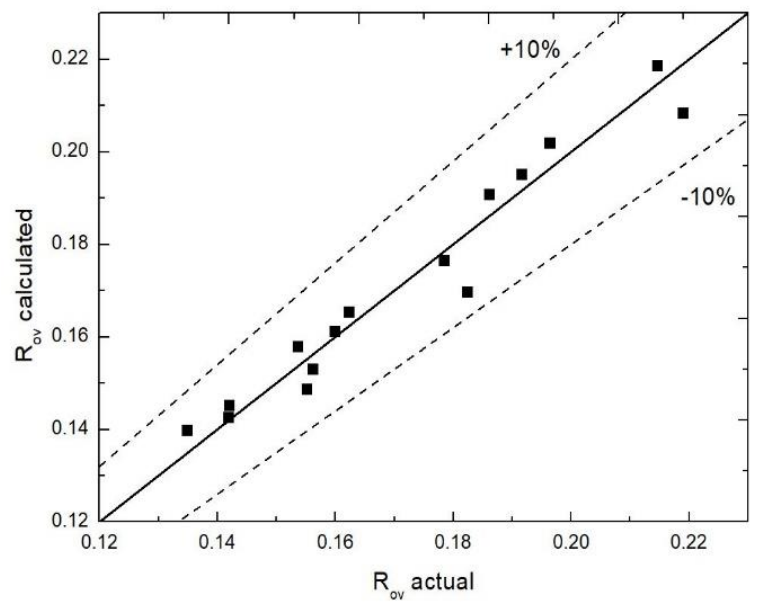


Fig. 3 Validation graph of $\mathrm{R}_{\mathrm{ov}}$ actual to $\mathrm{R}_{\mathrm{ov}}$ calculated

$$
\begin{gathered}
\Delta T_{l m}=\frac{\Delta T_{1}-\Delta T_{2}}{\ln \left(\Delta T_{1} / \Delta T_{2}\right)}, \Delta T_{1}=T_{w, \text { in }}-T_{r, \text { out }}, \Delta T_{2}=T_{w, \text { out }}-T_{r, \text { in }} \\
U=\frac{Q_{w}}{A \Delta T_{l m}} \\
Q_{w}=\dot{m}_{w} C_{p, w} \Delta T_{w}
\end{gathered}
$$

where $Q_{w}$ denotes the heat gain from the evaporator, $A$ denotes the heat transfer area of the PHE, and $\Delta T_{l m}$ denotes the LMTD. The properties of the refrigerant was obtained using REFPROP 10.0 database [4]. The total thermal resistance of the PHE, as shown in Eq. (8), can be obtained by the sum of the heat transfer coefficients of the water-side and refrigerant-side, and the conduction resistance.

$$
\frac{1}{U}=\frac{1}{h_{r}}+\frac{1}{h_{w}}+R_{c o n d}
$$

\subsection{Two-phase frictional pressure drop}

As shown in Eq. (9), the total pressure drop in the plate heat exchanger is composed of pressure drops by gravitation, acceleration, friction, and inlet/outlet ports.

$$
\Delta P_{\text {total }}=\Delta P_{\text {grav }}+\Delta P_{a c c}+\Delta P_{\text {fric }}+\Delta P_{\text {port }}
$$

Pressure drops by the gravitation and acceleration are shown in Eqs. (10) and (11), respectively [5].

$$
\begin{gathered}
\Delta P_{\text {grav }}=g L \rho_{m} \\
\Delta P_{a c c}=v_{f g} G^{2} \Delta x
\end{gathered}
$$

Also, the port pressure drop can be calculated by Eq. (12) [6].

$$
\Delta P_{p o r t} \cong 0.75 u_{m}^{2} \rho_{m}
$$

Consequently, the two-phase frictional pressure drop was calculated by Eqs. (9) - (12), and the two-phase friction factor $f_{t p}$ was calculated by Eq. (13).

$$
f_{t p}=-\frac{\rho_{m} D_{h}}{2 G^{2} L} \Delta P_{\text {fric }}
$$

\section{Results and discussion}

\subsection{Heat transfer coefficient}

Fig. 4 shows the evaporation heat transfer coefficient of R32 in the plate heat exchanger at a heat flux of $6.45 \mathrm{~kW} / \mathrm{m}^{2}$ and saturation temperatures of $5{ }^{\circ} \mathrm{C}$ and $15{ }^{\circ} \mathrm{C}$. In the vapor qualities of 0.05 to 0.9 , the heat transfer coefficient increased with the vapor quality. Since the forced convective boiling was the dominant heat transfer mechanism, the evaporation of the liquid to vapor phase accelerated with an increase in the vapor quality, promoting heat transfer. The heat transfer coefficient also increased with an increase in the mass flux. 
(a)

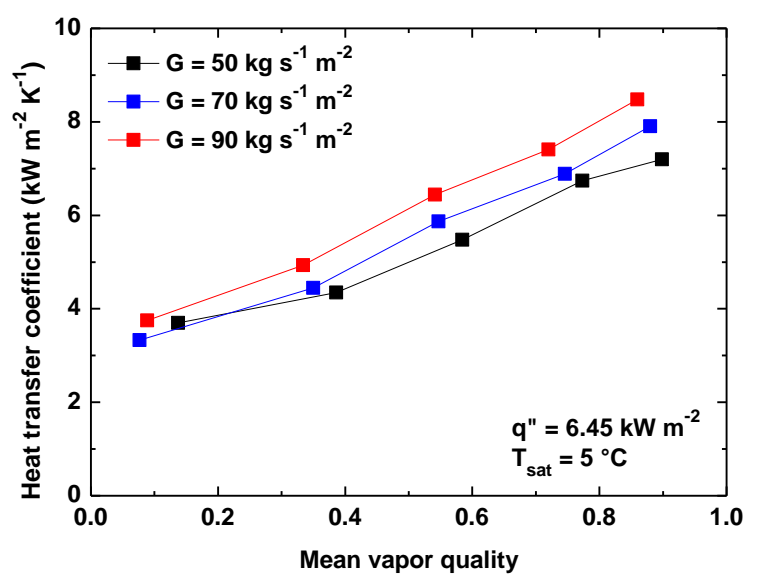

(b)

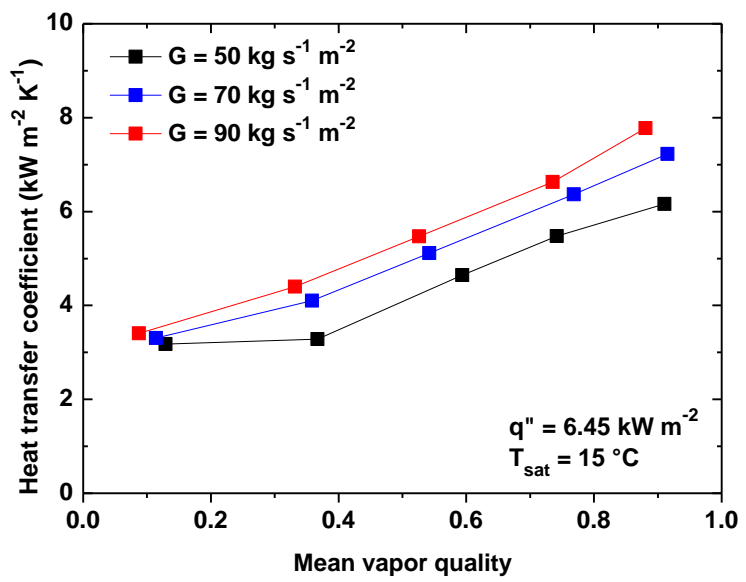

Fig. 4 Heat transfer coefficient of R32 with respect to mass flux at (a) $\mathrm{T}=5^{\circ} \mathrm{C}$ and (b) $\mathrm{T}=15^{\circ} \mathrm{C}$.

Fig. 3 shows the heat trasnfer coefficient of R32 compared to R410A at various mass fluxes and vapor qualities with a heat flux of $6.45 \mathrm{~kW} / \mathrm{m}^{2}$ and a saturation temperature of $5{ }^{\circ} \mathrm{C}$. At the same condtions, the heat transfer coefficient of R32 was higher than R410A because of its higher liquid thermal conductivity and lower vapor density.

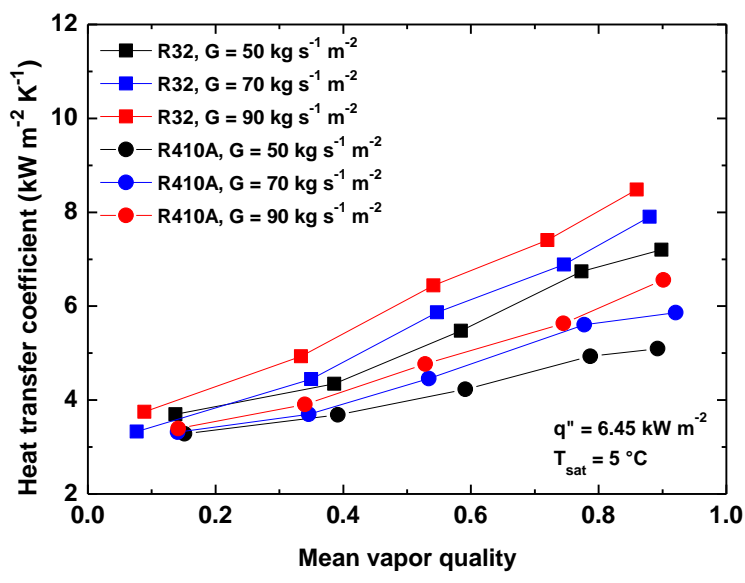

Fig. 5 Heat transfer coefficients of R32 and R410A with respect to mass flux at $\mathrm{T}=5^{\circ} \mathrm{C}$.

\subsection{Frictional pressure drop}

Fig. 6 shows the frictional pressure drop and friction factor of R32 at various mass fluxes and vapor qualities with a heat flux of $6.45 \mathrm{~kW} / \mathrm{m}^{2}$ and saturation temperature of $5{ }^{\circ} \mathrm{C}$. The frictional pressure drop increased with the vapor quality and the increasing trend became dramatic as the vapor quality incerased. This was because the flow velocity increased as the vapor quality and mass flux increased, resulting in the higher friction. In relatively low vapor quality region $(0.05-0.4)$, the friction factor decreased as the vapor quality increased because the decreasing rate of $\rho_{m}$ in Eq. (13) was larger than the decreasing rate of $\Delta P_{\text {fric }}$. On the other hand, at vapor qualities higher than 0.4 , the friction factor tended to increase slightly, indicating large enough $\Delta P_{\text {fric }}$. This was because the friction increased as the vapor quality increased. 

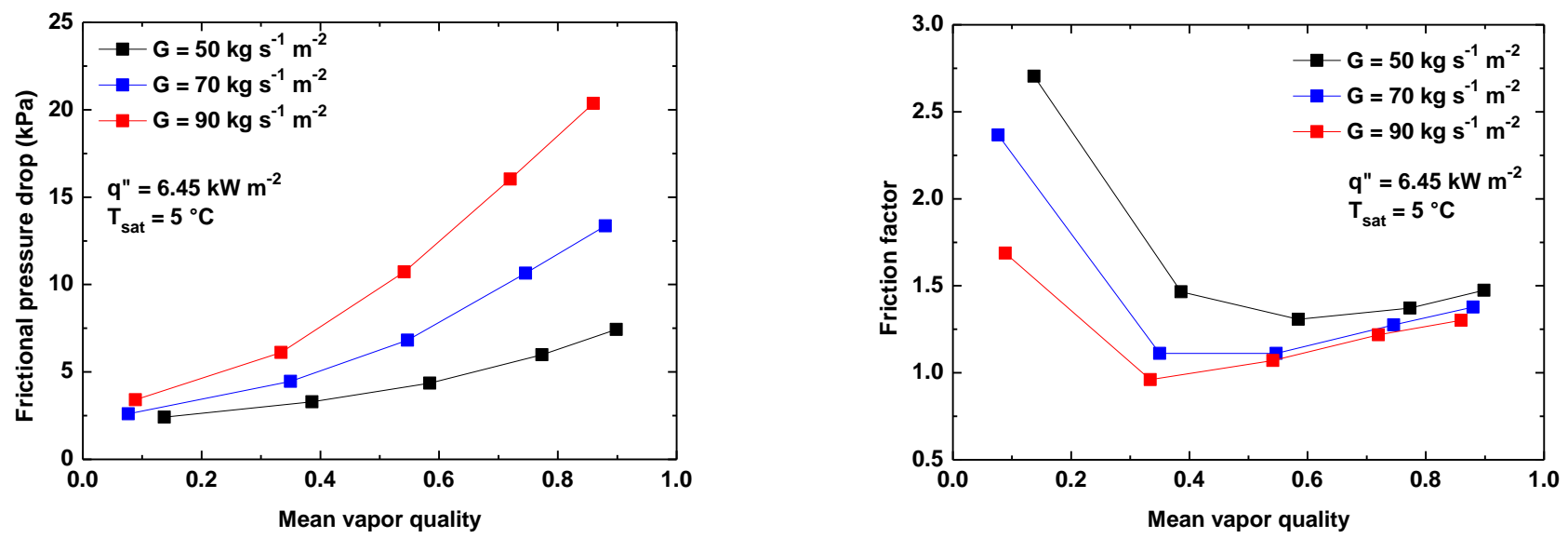

Fig. 6 (a) Frictional pressure drop and (b) friction factor of R32 with respect to mass flux and vapor quality.

Fig. 7 shows the frictional pressure drop and friction factor of R32 compared to R410A. The frictional pressure drop of R32 was higher than R410A because the effect of the lower density of R32 was more dominant even with the lower viscosity compared to R410A. However, the friction factor of R32 was lower than R410A due to the effect of the lower density, as shown in Eq. (14).

(a)

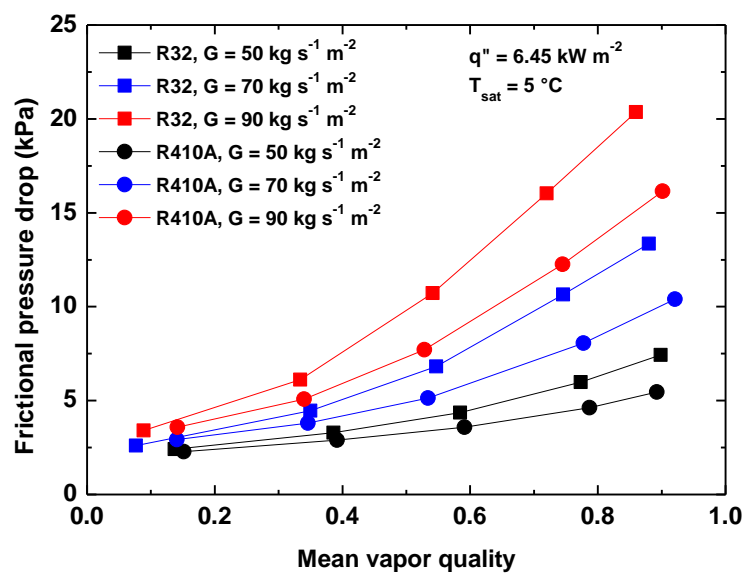

(b)

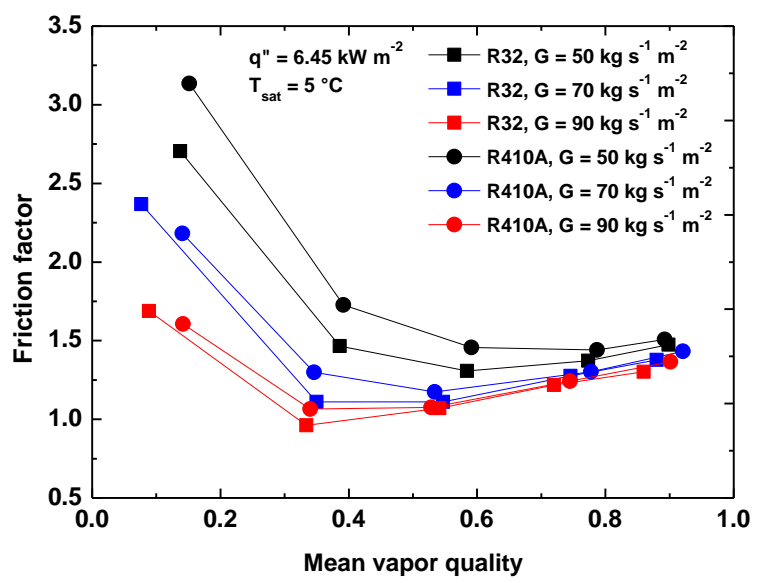

Fig. 7 (a) Frictional pressure drop and (b) friction factor of R32 compared to R410A.

\section{Conclusion}

The evaporation heat transfer and frictional pressure drop characteristics of R32 were measured in a plate heat exchanger with a chevron angle of $60^{\circ}$. The evaporation heat transfer coefficient of R32 in the plate heat exchanger increased as the mass flux and vapor quality increased. Furthermore, the heat transfer coefficient of R32 was higher than R410A in all conditions owing to the higher thermal conductivity and lower vapor density of R32, promoting the forced convective boiling. Additionally, the frictional pressure drop of R32 increased with increases in the mass flux and vapor quality. The friction factor decreased significantly to a certain vapor quality and then slightly increased depending on which factor had the greater impact at each condition. 


\section{References}

[1] Schulz, M., and D. Kourkoulas. "Regulation (EU) No 517/2014 of the European Parliament and of the council of 16 April 2014 on fluorinated greenhouse gases and repealing Regulation (EC) No 842/2006." Off. J. Eur. Union 2014.517 (2014): L150.

[2] Martin, Holger. "A theoretical approach to predict the performance of chevron-type plate heat exchangers." Chemical Engineering and Processing: Process Intensification 35.4 (1996): 301-310.

[3] Wilson, E.E. "A basis for rational design of heat transfer apparatus." The J. Am. Soc. Mech. Engrs. 37 (1915): $546-551$.

[4] Lemmon, E. W., Bell, I. H., Huber, M. L., \& McLinden, M. O. "NIST standard reference database 23: Reference fluid thermodynamic and transport Properties-REFPROP, Version 10.0, National Institute of Standards and Technology." Standard Reference Data Program, Gaithersburg (2018).

[5] Collier, J.G., and J.R. Thome. Convective boiling and condensation. Clarendon Press, 1994.

[6] Shah, R.K., and W.W. Focke. "Plate heat exchangers and their design theory." Heat Transfer Equipment Design 227 (1988): 254. 